\title{
POÉTICAS VISUAIS DE UMA GUARANI: TRANSFORMAÇÕES E CUIDADOS COM O CORPO FEMININO
}

\author{
RANDRA KEVELYN BARBOSA BARROS ${ }^{1}$ \\ $P U C-R J, B R A S I L$ \\ https://orcid.org/0000-0003-3881-1063
}

\begin{abstract}
RESUMO: Os artistas indígenas têm expressado percepções cosmológicas de diferentes povos por meio de produções em múltiplas linguagens. Gennis Ara'í Timóteo (2020), Guarani da aldeia M'Biguaçu, trabalha as conexões entre corpos femininos e outros seres na pintura de suas telas, nas quais ressalta os ciclos de vida das mulheres de seu povo. O objetivo desse artigo é examinar poéticas visuais tecidas por Gennis Timóteo em suas telas, buscando destacar a relação do corpo das mulheres Guarani com a terra; e a sabedoria de cuidado que a comunidade pratica durante os processos de transformações corporais. Para tanto, recorre-se às discussões sobre vida (Krenak, 2019, 2020); relação (Glissant, 2005, 2017); mulheres indígenas em conexão com a terra (Kuawá Apurinã, 2019). O percurso metodológico do estudo se ancora na pesquisa bibliográfica, com abordagem qualitativa, tendo em vista o exercício de análise crítica da produção visual de Gennis Timóteo (2020). Assim, a investigação demonstra gestos de protagonismo feminino nas artes, apontando que a linguagem visual pode ser um instrumento para comunicar a sabedoria e as vivências das mulheres Guarani.
\end{abstract}

PALAVRAS-CHAVE: Autoria indigena, Artes visuais, Mulheres Guarani, Corpo feminino, Gennis Timóteo.

\begin{abstract}
Indigenous artists have expressed cosmological perceptions of different peoples through productions in multiple languages. Gennis Ara'i Timóteo (2020), a Guarani from the M'Biguaçu village, works on the connections between female bodies and other beings in the painting of her canvases, in which she highlights the life cycles of the women of her people. The aim of this article is to examine the visual poetics woven by Gennis Timóteo on her canvases, seeking to highlight the relationship of the Guarani women's bodies with the land and the wisdom of care that the community practices during the processes of bodily transformation. To this end, we draw on discussions about life (Krenak, 2019, 2020); relationship (Glissant, 2005, 2017); indigenous women in connection with the land (Kuawá Apurinã, 2019). The methodological path of the study is anchored in bibliographical research, with a qualitative approach, in view of the exercise of critical analysis of the visual production of Gennis Timoteo (2020). Thus, the research demonstrates gestures of female protagonism in the arts, pointing out that visual language can be an instrument to communicate the wisdom and experiences of Guarani women.
\end{abstract}

KEYWORDS: Indigenous authorship, visual arts, Guarani women, Female body, Gennis Timóteo.

\footnotetext{
${ }^{1}$ Doutoranda no Programa de Pós-graduação em Literatura, Cultura e Contemporaneidade (PPGLCC), pela Pontifícia Universidade Católica do Rio de Janeiro (PUC-RIO), com financiamento CNPq. E-mail: randrakevelyn@gmail.com
} 


\section{Expressões artísticas: a perspectiva indígena}

Em Cipó Tupi (2021)², documentário dirigido por Léo Mendez e Célia Tupinambá, indígenas Tupinambá - situados em Olivença, sul do estado da Bahia - relatam o processo de confecção de cestos, balaios, caçuás, vassouras, usando cipós de patioba. É necessário agir com cuidado ao retirar da mata esses materiais, um olhar atento na seleção das plantas para que suas "mães" não sejam arrancadas e ocorra um desequilíbrio na natureza.

Há uma diversidade de tipos de cipó e cada espécie é mais adequada para a confecção de um objeto específico. Cipó uruba, juçara, timborana são alguns nomes que compõem essa variedade. As técnicas de confecção são múltiplas, podendo ser vistas no momento em que os artesãos fazem o "remate"3 no cesto, por exemplo. Para os Tupinambá de Olivença, confeccionar objetos com cipós de patioba é um fazer artístico e uma sabedoria ancestral, que foi transmitida oralmente e de maneira prática dentro da comunidade.

Cabe lembrar que, como explicam Els Lagrou e Lucia Velthem (2018, p. 134), "conhecimentos múltiplos - ambientais, técnicos, éticos, estéticos, mitológicos e rituais - são necessários para fabricar artefatos de uso cotidiano ou ritual". Nesse sentido, saberes de campos diversos são mobilizados e o fazer artístico é trabalhado em uma dimensão mais ampla. As técnicas de tecer, fiar, coletar sementes, amassar o barro, entre outras, contribuem para a elaboração de esteiras, redes, colares, vasilhas, potes, e vários objetos. Por vezes, essas produções são consideradas artefatos em virtude da materialidade que adquirem, artes com uma função utilitária concreta e elaboradas de forma manual, exigindo habilidade técnica nas mãos.

Para além da confecção dos artefatos, os indígenas também produzem representações gráficas inscritas no próprio corpo. Os grafismos são elaborados de acordo com as especificidades de cada povo e significam dentro daquela comunidade. São também um instrumento de comunicação visual, pois as formas geométricas dos traçados transmitem informações importantes sobre a pessoa na qual os desenhos estão inscritos. É possível ler as representações visuais pintadas na tela do corpo, considerando a função simbólica desse tipo de escritura.

Os aspectos pictóricos e a dimensão de comunicação milenar que os grafismos evocam são discutidos por Márcia Wayna Kambeba (2020). A estudiosa explica que a pintura também é realizada com a intenção de proteção em alguns povos, pois os traçados fortalecem o espírito e defendem o corpo físico. Alguns significados, pensando o contexto de seu povo Omágua/Kambeba, são explorados pela autora:

\footnotetext{
${ }^{2}$ Documentário exibido durante o Festival de Cinema Cine Kurumin 2021, entre os dias 14 mar. 2021 a 15 abr. 2021.

${ }^{3}$ Processo de acabamento do cesto, quando é necessário realizar os ajustes finais com o cipó.
} 
Espaço Ameríndio

Os grafismos são marcas do espaço-tempo em nós, contam histórias, e desenhá-los na pele é dar espaço para a história falar. Existe um grafismo que representa asas de borboletas; seu desenho lembra uma sequência de " $w$ ". Simboliza toda a metamorfose da larva para se tornar uma borboleta. Assim, os Omágua/Kambeba percebem esse grafismo como representação de uma evolução, de um crescimento (KAMBEBA, 2020, p. 49).

As marcas sociais pintadas nos indígenas contornam diferentes desenhos, representando, por vezes, animais e elementos da natureza que possuem um sentido para a comunidade. Portanto, as representações visuais expressam conhecimentos milenares e são mecanismos para comunicar significados culturais dos povos.

Os artefatos e os desenhos de grafismos na tela do corpo indicam a multiplicidade de estéticas indígenas que são produzidas no Brasil e em outros países do planeta. No entanto, é importante destacar também que os artistas têm ampliado o seu repertório para utilizar diferentes recursos e suportes comuns na sociedade nacional: "[...] são escritores de romances, contos e mitos; são pintores, desenhistas, cantores, dançarinos e performáticos; são artesãos, tecelões, ceramistas, designers; fazem filmes, vídeos, instalações, fotografias, sítios virtuais, discos e livros" (RANGEL, 2009 , p. 12). Essas diferentes produções expandem o seu espaço de circulação para além das comunidades e encontram os não indígenas para estabelecer um diálogo intercultural.

As linguagens contemporâneas utilizadas pelos artistas tanto auxiliam na luta por direitos quanto também expressam percepções cosmológicas ligadas a um povo. A pluralidade de trabalhos artísticos que emerge dessa cena mostra a potência do gesto de ressignificar instrumentos que foram impostos pela sociedade dominante. Essa atitude contribui para a criação de projetos artísticos próprios, que articulam as tecnologias com os conhecimentos ancestrais.

O pensamento de que todos os seres são interligados é frequentemente encontrado nas filosofias indígenas e traduzido em representações artísticas. O sujeito existe em relação com outros seres que compõem o planeta. Assim, as noções de vida e relação podem ser combinadas para o entendimento de que a Terra é um corpo feminino que mantém a existência de humanos, animais, vegetais, minerais, seres microscópicos. A compreensão dessa teia de relações nos permitirá analisar as poéticas visuais de Gennis Timóteo (2020), as quais traduzem conhecimentos Guarani de atenção às fases do corpo feminino devido à importância da mulher como pessoa que gera a vida. 
Espaço Ameríndio

\section{Vida em relação: mulher e Mãe Terra}

Ailton Krenak (2019) tem construído críticas ao modo de pensar hegemônico, o qual é orientado por uma linha evolutiva em busca de desenvolvimento e progresso. Nesse sentido, o ser humano é visto como centro do planeta e as pessoas constituem a única possibilidade de humanidade. Essa coesão exclui diferentes formas de existência que estão vivas e fazem parte da Terra. Até mesmo os humanos enfrentaram o processo de serem apartados do organismo vivo que lhes permite a existência (a Terra).

Segundo o pensador, "o Antropoceno tem um sentido incisivo sobre a nossa existência, a nossa experiência comum, a ideia do que é humano. $\mathrm{O}$ nosso apego a uma ideia fixa de paisagem da Terra e da Humanidade é a marca mais profunda do Antropoceno" (KRENAK, 2019, p. 58). A paisagem seria transformada em prédios que desmatam a natureza; e a humanidade se configuraria de uma maneira restrita ao homem. Questionando esse pensamento que está presente no imaginário da sociedade contemporânea, o autor discute possibilidades de existências construídas na relação com outros seres, o que caracteriza várias cosmologias indígenas.

Uma outra concepção de vida é necessária para rasurar a hegemonia do antropoceno e expandir as possibilidades de existência. A noção de vida precisa, portanto, ser compreendida de maneira ampla:

A vida atravessa tudo, atravessa uma pedra, a camada de ozônio, geleiras. A vida vai dos oceanos para a terra firme, atravessa de norte a sul, como uma brisa, em todas as direções. A vida é esse atravessamento do organismo vivo do planeta numa dimensão imaterial. Em vez de ficarmos pensando no organismo da Terra respirando, o que é muito difícil, pensemos na vida atravessando montanhas, geleiras, rios, florestas. A vida que a gente banalizou, que as pessoas nem sabem o que é e pensam que é só uma palavra. Assim como existem as palavras "vento", "fogo", "água", as pessoas acham que pode haver a palavra "vida", mas não. Vida é transcendência, está para além do dicionário, não tem uma definição (KRENAK, 2020, p. 2829).

Todos os seres que constituem a Terra são atravessados pela vida e integram a pluralidade de existências no planeta. Nessa perspectiva, cabe destacar a interligação dessas diferentes humanidades, pois há uma conexão na qual o que acontece com uma espécie impacta todas as outras.

A concepção de que a vida está em um plano para além do humano orienta práticas de diferentes comunidades. Ao mesmo tempo em que tudo é vivo, o corpo do ser humano existe em relação com outros corpos de 
diversos seres. O sentido da relação nesse processo pode ser compreendido a partir do diálogo com as reflexões de Édouard Glissant (2005).

A partir dos questionamentos "como ser si mesmo sem fechar-se ao outro, e como abrir-se ao outro sem perder a si mesmo?" (GLISSANT, 2005, p. 28), Glissant (2005) discute a relação como um operador conceitual, poético, subjetivo, prático e político que considera a importância da diferença. $O$ autor acredita que é necessário retornar ao pensamento présocrático "de que o ser é relação, ou seja, o ser não é absoluto, o ser é relação com o outro, relação com o mundo, relação com o cosmos" (GLISSANT, 2005, p. 37). Nesse sentido, nos termos glissantianos, existe uma rede de relações que não pode ser ignorada e aciona um pensamento para as interações culturais e para as diferenças.

O filósofo entende que o diálogo entre os grupos deve ser estabelecido na perspectiva da identidade-relação, a qual está aberta para outras culturas (GLISSANT, 2017). Não se fecha em si mesma e permite o processo de transformação nesse contato, porém não é absorvida ou apagada. Mesmo no contato com o outro, a diferença própria continua sendo mantida e não há a pretensão de apagar as práticas culturais com as quais se relaciona. Com isso, o território se torna lugar de convivência, de partilha de saberes e interação dos grupos.

Deslocando as concepções glissantianas para o contexto indígena, de fato é possível afirmar que a construção de uma teia de relações com o universo é um dos fundamentos de várias culturas. Inclusive, a vida é possível devido à relação e o eu absoluto não existe, já que não pode se sustentar autonomamente. No entanto, cabe lembrar que o autor dialoga com formulações pré-socráticas, que pelo termo demonstram estar inseridas em outro tempo e espaço (linha progressiva do tempo europeu). Em Abya Yala, práticas de relação já eram estabelecidas sem atender a uma demanda do pensamento europeu.

Quanto à identidade-relação, o crítico entende que esse tipo de subjetividade é primordialmente construído entre pessoas, embora cite a interação com os cosmos quando expõe o pensamento pré-socrático. Cabe, portanto, expandir essa ideia levando em consideração que diversos seres têm vidas e o humano interage com o não humano na perspectiva de diferentes povos. Nesse sentido, a identidade-relação se torna interativa com todo o planeta, pois o outro corresponde também a todos aqueles que são excluídos por serem objetificados pelos interesses antropocêntricos (plantas, rios, pedras).

A relação que vários povos originários estabelecem com o planeta é tecida no campo afetivo, pois a terra pode ser considerada uma mãe que dá vida a todos os seres. Abordando o pensamento das mulheres indígenas a partir do olhar Apurinã, Kuawá Apurinã (2019, p. 20) explica: "a Terra é fêmea e geradora de nossas vidas, temos de cuidar dela, pois ela não nos negará nada". A natureza e o corpo feminino são concebidos a partir de uma conexão indissociável: 
Espaço Ameríndio

E como não pensamos que a terra é algo capitalizado e bem de consumo, entendemos como uma parental ancestral parte de nosso corpo e espírito. E cuidar da Terra, que chamam de natureza, é cuidar de nós mesmas, pois a terra é nossa mãe criadora de nossa essência. E o que nos dá vida e amor. Ouvimos as vozes de nossos troncos velhos, que são como árvores antigas e frondosas que nos ensinam sobre nós e que viveram antes de nós. Os nossos saberes estão nos espíritos das florestas; fauna e flora e estes seres nos encantam e (re) encantam a partir de nossas ancestralidades e amor a nossa mãe terra (APURINÃ, 2019, p. 13).

A defesa do território é também a valorização do sagrado feminino que gera, cuida e alimenta todas as existências no planeta. A parente ancestral é considerada uma mulher e esses corpos são marcados pela sabedoria das matas, dos animais e outros seres das florestas. Diferentes nações indígenas compartilham desse pensamento, elaborando uma forma própria de entender e tratar as etapas da vida das mulheres. A menstruação, gestação e parto adquirem significados que expressam a identidade-relação das indígenas e podem ser representados pictoricamente, como ocorre no trabalho de Gennis Timóteo (2020). A artista consegue traduzir visualmente a percepção cosmológica de seu povo acerca do tratamento direcionado à mulher durante os processos de transformação do corpo.

\section{Gennis Timóteo: corpo, sabedoria e cosmologia em pinturas}

Gennis Ara'í Martins Timóteo nasceu no estado de Santa Catarina, em 1982. Filha do povo Guarani, mora na comunidade Yynn Moroti Wherá, município de Biguaçu (Santa Catarina). Graduada em Licenciatura Intercultural Indígena do Sul da Mata Atlântica, pela Universidade Federal de Santa Catarina (UFSC), atua como professora na escola indígena. É uma artista que trabalha com diferentes formas de expressão, como cerâmica, pinturas, grafismos, entre outros.

Para o seu estudo monográfico, Timóteo $(2020)^{4}$ construiu representações visuais em telas para introduzir cada capítulo do texto. A monografia estuda os ciclos de vida das mulheres guarani, tomando como ponto de partida as integrantes da família da autora. Aqui nota-se a necessidade de a estudiosa se expressar de outra maneira para além do registro escrito acadêmico. Por meio da arte, seria possível construir também imaginários que ilustram a relação do corpo feminino com a Mãe Terra e as etapas vivenciadas pela mulher ao longo de sua trajetória. Cada

\footnotetext{
${ }^{4}$ Intitulada "Kunhangue arandu rekó, ta'ánga re a'egui nhembopara: sabedoria dos ciclos de vida das mulheres guarani em pinturas e palavras" (2020), a monografia discute como o povo Guarani pensa as transformações vivenciadas pela mulher desde a primeira menstruação até a menopausa.
} 
pintura instiga o pensamento do leitor antes de começar a se debruçar sobre o texto, tendo em vista que as telas antecedem as palavras em cada seção.

É importante destacar a relevância da produção de conhecimento de Gennis Timóteo (2020) por apresentar o resumo da pesquisa em língua portuguesa e no idioma guarani. Ainda é negado no país o direito à pluralidade linguística, já que o idioma hegemônico se impõe, nega a existência de várias línguas e até mesmo apaga diferentes possibilidades comunicativas, pois se instala também nos contextos indígenas. Escrever o resumo em guarani já é em si um gesto de rasura, mostrando a necessidade de entender que, para além das línguas estrangeiras geralmente solicitadas nesse tipo de texto que são utilizadas em outros países (inglês, espanhol, francês, entre outras), no próprio Brasil, diversos idiomas diferentes do português são falados e podem ser valorizados no resumo. São línguas estrangeiras que convivem dentro do país, embora sejam frequentemente ignoradas.

Os trabalhos pictóricos da artista, além de estarem presentes em sua monografia, estão expostos na plataforma virtual "Fagtar: a força delas"5, que reúne produções de mulheres indígenas de diferentes povos e regiões do país. O portal divulga palavras, imagens e pensamentos construídos por um grupo invisibilizado por sofrer com uma dupla opressão: racial e de gênero. $O$ ato de elaborar a plataforma foi uma iniciativa extremamente importante para questionar o apagamento das mulheres indígenas e mostrar o quanto elas estão autonomamente criando redes que as evidenciam como agentes de suas próprias histórias.

Gennis Timóteo (2020) desenvolve algumas particularidades no seu processo criativo: os quadros são elaborados com tintas para estampa e moldura de bambu. Sobre o tecido, a artista traça os desenhos e depois os emoldura. Os materiais utilizados para a confecção das telas foram adaptados, já que não era possível trabalhar com recursos totalmente naturais, como tintas extraídas de plantas, por exemplo, mas ainda assim o procedimento demonstra uma preocupação com a natureza. Timóteo (2020, p. 16) explica o uso de bambu seco: "o bambu foi mais fácil de encontrar porque há na aldeia, mas só utilizo bambus secos, com o objetivo de preservar o que resta da aldeia". A responsabilidade com a aldeia é fundamental nesse sentido. Existe, portanto, uma combinação entre materiais que são retirados diretamente da comunidade e recursos industrializados, dessa fusão emerge os quadros.

A artista retrata visualmente diferentes etapas vivenciadas pela mulher durante as transformações de seu corpo, que exigem cuidados específicos na cultura guarani. Dentre essas fases, destacam-se três para fins analíticos: menarca, gravidez e menopausa, que correspondem a faixas etárias

\footnotetext{
${ }^{5}$ Lançada em abril de 2020, a plataforma é elaborada com a parceria de não indígenas e compila material de autoria feminina indígena, que se estende das artes até produções científicas. Na seção "Expressões", a produção de Gennis Timóteo está exposta, apresentando o mesmo nome do título da monografia: https://fagtar.org/expressoes/expogennis/
} 
Espaço Ameríndio

diversas. O período da primeira menstruação sugere o início de um ciclo semelhante às mudanças vivenciadas pelas árvores:

Figura 1: Memby ryru (útero)

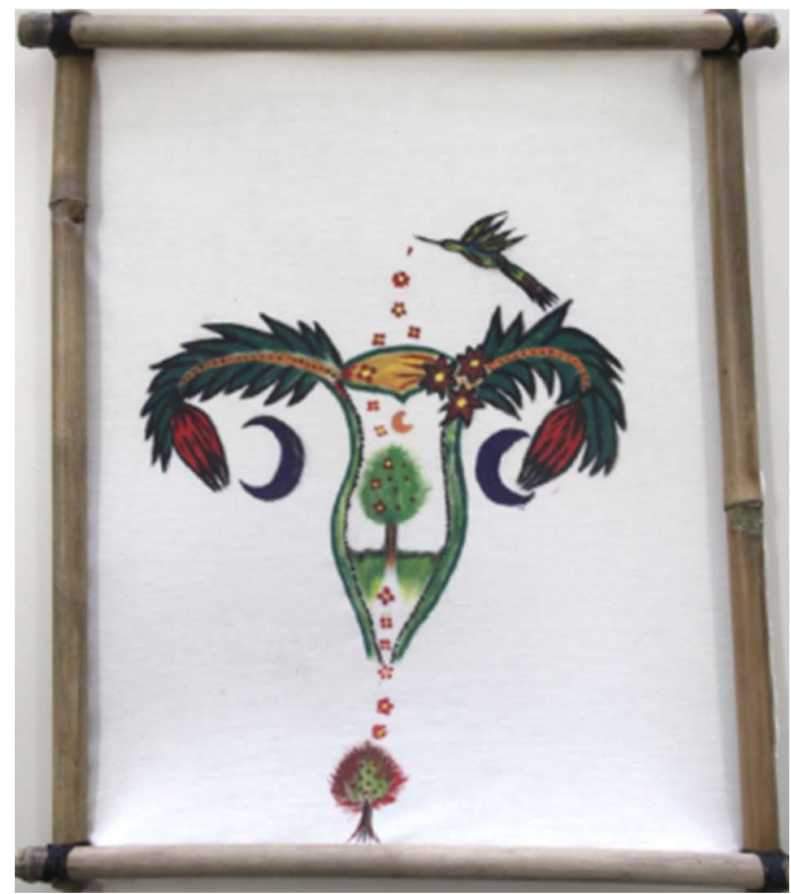

Fonte: TIMÓTEO, Gennis. Memby ryru (útero). 2020. Pintura em tela (tinta de estampa e moldura de bambu), página 25.

A imagem não recorre a uma visualidade convencional para retratar a menarca, na qual o útero, o ovário e o sangue estariam representados de maneira biológica e próxima ao real. O conhecimento cosmológico orienta o pensamento sobre a mudança do corpo durante a primeira menstruação. $E$ o útero é mais do que uma parte integrante da anatomia da mulher. Nele, ocorrem transformações semelhantes aos ciclos das plantas. Na imagem, o beija-flor deposita sementes em forma de pequenas flores no útero. As sementes dão origem ao embrião de árvores que, com o tempo, crescerão e florescerão, quando os óvulos forem fecundados. É interessante notar que as flores no bico do beija-flor são eliminadas, em forma de sangue menstrual, pela vagina.

As trompas são ramos cobertos de verde. Do lado esquerdo e direito das trompas, observamos pontinhos pretos que representam os óvulos. As flores, ao final dos ramos, estão fechadas e ainda desabrocharão. Há uma lua crescente acompanhando e guiando a mudança de cada flor, o que demonstra a influência dos astros nesse processo. É importante lembrar: "a lua é um ser sagrado que representa o símbolo feminino guarani que influencia a vida e o modo de ser de uma Guarani" (TIMÓTEO, 2020, p. 26). 
Ao menstruar, a mulher guarani entra em djatchy (está na lua), como explica Gennis Timóteo (2020), sendo necessário vivenciar rituais específicos em cada povo e seguir orientações para a limpeza do corpo. A autora cita a própria necessidade de cortar o cabelo e se aprofundar no conhecimento das plantas, especialmente da cura proveniente delas.

Beija-flor, sementes, lua e brotos de árvores compõem a representação visual da primeira menstruação e sugerem que a anatomia feminina é também terra. Dentro do memby ryru, há um articulado sistema de vida que funciona de maneira semelhante ao processo de germinação cultivado por Nhandetchy (Mãe Terra). As sementes (óvulos) saem da vagina em forma de sangue, até o momento em que serão germinadas (fecundação) e as flores desabrocharão, juntamente com o desenvolvimento das árvores (formação do embrião até se tornar um bebê). Tal como Nhandetchy possui um corpo feminino, a mulher é terra em processo de cultivo quando está na lua. As transformações da mulher-terra envolvem plantas, astros, cuidados com o corpo, diversos rituais que expõem o quanto o sistema de vida está em relação com diferentes seres. Estar grávida também é um momento de intensas mudanças para as mulheres guarani:

Figura 2: Ipuru'a (estar grávida)

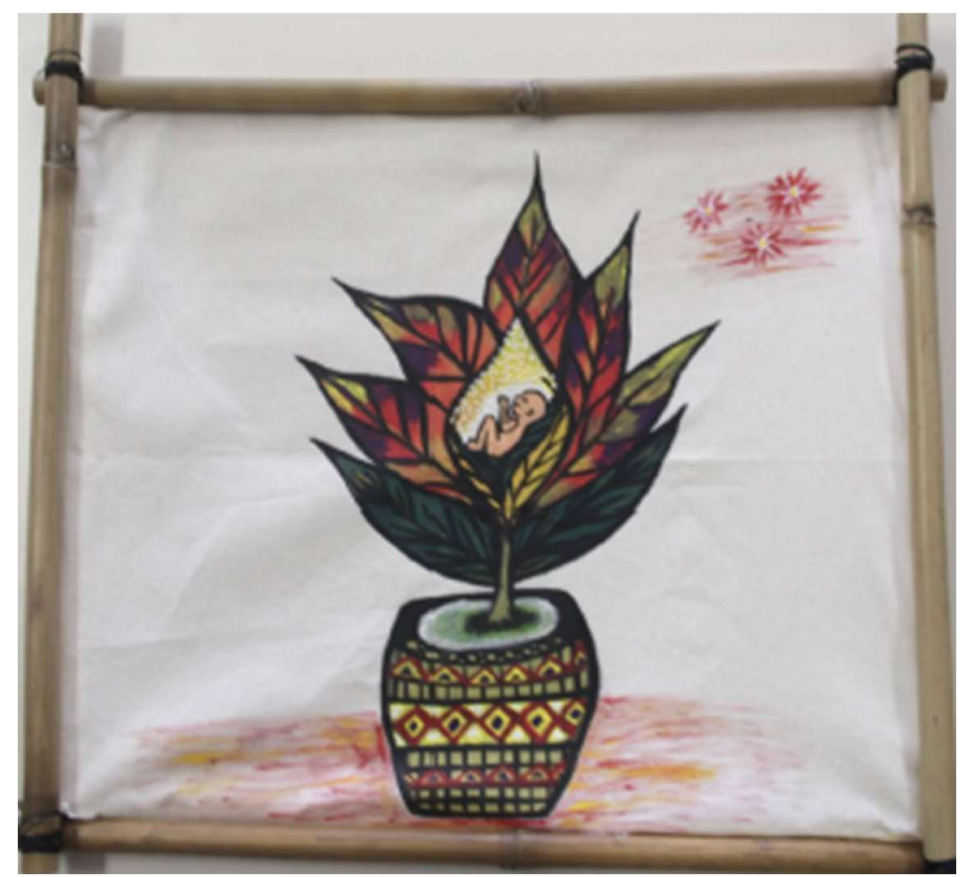

Fonte: TIMÓTEO, Gennis. Ipuru'a (estar grávida). 2020. Pintura em tela (tinta de estampa e moldura de bambu), página 32.

Diferente da primeira tela, na figura 2, não há a representação de um útero, no qual o bebê convencionalmente é desenvolvido. Dois elementos se 
destacam: o cesto e a planta, ambos são geradores do embrião. O cesto é marcado pela pintura de figuras geométricas que podem ser associadas aos grafismos. A haste da planta se desenvolve em cima do cesto e, além de dar origem a duas folhas verdes grandes, cresce com folhas coloridas que guardam o broto de uma flor dentro de si. Há uma energia que colore esses elementos da planta, podendo ser interpretada tanto como o carinho e cuidado que a mãe direciona ao bebê; quanto a própria força do embrião que emana ainda mais vida dentro do corpo da mulher.

Cabe lembrar alguns significados do artefato dentro da comunidade: "fomos criadas de um cesto de taquara por Nhanderu e isso faz parte da criação divina da mulher guarani" (TIMÓTEO, 2020, p. 32). Nessa perspectiva, a narrativa de origem das mulheres para os guarani orienta a função do cesto na imagem, visto que o artefato representa o corpo feminino. Como um objeto pode adquirir a relevância de ser o material do qual a mulher é criada? Para entender esse sentido, é necessário pensar no valor dos artefatos indígenas, que não são objetos desprovidos de simbolismo.

Ao analisar os materiais confeccionados pelos Wayana, Lucia Velthem (2010) percebe que existe um processo de corporificação dos objetos, encarados como humanos:

A elaboração plástica, dotada de sentido decorativo não se restringe aos humanos, mas também se aplica aos artefatos, como cestos, remos, recipientes cerâmicos, bancos, cuias, cabaças, em que se percebem variações formais, reveladoras das técnicas decorativas empregadas, como a pintura, as incisões, as amarrações. Humanos e objetos são igualmente decorados porque compartilham uma série de faculdades, entre as quais a antropomorfia, uma vez que para muitos povos indígenas os artefatos são compreendidos enquanto seres corporificados ou antes representam corpos ou partes deles (VELTHEM, 2010, p. 26).

Os artefatos, na perspectiva de muitos povos, são corporificados, podendo adquirir as pinturas que geralmente são realizadas nos corpos das pessoas. Esse pensamento nos ajuda a compreender por que a mulher guarani foi criada de um cesto de taquara e também a razão pela qual o artefato foi colorido com diversos grafismos. Nesse sentido, como a mulher foi constituída por um cesto, o objeto se torna a própria figura feminina, com a capacidade de gerar o embrião de uma nova vida.

$\mathrm{Na}$ imagem 2, o artefato é responsável por criar o invólucro na forma de uma planta, na qual o broto de uma flor será desenvolvido. Na cena, as pétalas encontram-se fechadas, porém, dentro delas, observamos o corpo de um bebê. O embrião é uma semente que, após completar todos os níveis de desenvolvimento, se tornará uma flor aberta. Ou seja, existe uma 
interação entre diferentes seres: cesto, planta e bebê, todos ligados para que um novo ser humano possa ser formado.

Mais uma vez, a mulher precisa de cuidados especiais. A atenção é intensificada, já que o corpo da mãe está hospedando outro ser. Alguns rituais precisam ser seguidos:

Quando uma guarani engravida, ela e o pai da criança também passam por rituais nos quais devem cumprir de acordo com as regras para que o bebê não sofra as consequências. A futura mãe deve tirar do corpo todos adornos que possuem cordão, por exemplo, colares, pulseiras, cintos e brincos. Não usar roupas muito apertadas porque isso poderá fazer mal a criança, ela poderá se enrolar no cordão umbilical e morrer mesmo no útero. Devem tomar muitos chás para dar energia ao bebê. Devem massagear bastante a barriga e o corpo para não sentir dor na hora do parto, deve levantar bem cedo para que o bebê não seja preguiçoso. A alimentação deve ser saudável tanto da mãe quanto do pai, porque isso também influencia na alimentação do bebê. Durante os três primeiros meses, é necessário repouso total porque é o período em que há maior risco à gravidez porque é uma fase de muita fragilidade (TIMÓTEO, 2020, p. 33-34).

A gravidez envolve toda a comunidade, tendo em vista a necessidade de assegurar a saúde da mãe e do bebê. Nesse sentido, a alimentação balanceada é essencial, assim como acreditar no poder das plantas para ingerir os chás necessários. Mesmo estando fora da comunidade, as mulheres guarani podem seguir as orientações de seu povo para esse período, pois "mesmo não estando na aldeia eu plantava minhas ervas medicinais em vasos" (TIMÓTEO, 2020, p. 34). É interessante pensar também que a gravidez na adolescência não é vista de maneira negativa no povo, já que é cultural o casamento mais cedo, assim como a construção da família.

Ipuru'a é um momento de atenção, cuidado, importante marco na vida da mulher. $O$ corpo enfrenta diversas mudanças que devem ser acompanhadas pela sabedoria dos Guarani. Será possível, portanto, ter uma gravidez tranquila caso todas as orientações sejam praticadas. Além disso, o trabalho pictórico mostra que a reprodução feminina pode ser representada sem expor necessariamente um elemento anatômico. $\mathrm{Na}$ perspectiva cosmológica, o cesto compõe a mulher e pode ser a figura dela, como a tela sugere. Do artefato, emerge a planta que guardará o embrião e será o receptáculo do novo ser. Mais uma vez, uma teia de relações é construída, sugerindo que existe uma identidade-relação da mulher ao estar interligada com seres em diferentes formatos (material, vegetal, entre outros).

As etapas vivenciadas pelo corpo feminino são múltiplas: transição de menina para mulher, com a menarca; possibilidade da gravidez; e também 
a menopausa, quando se torna anciã. É a fase na qual a existência feminina arquivou conhecimentos adquiridos com o seu povo:

Figura 3: Djatchy re noi veima (menopausa)

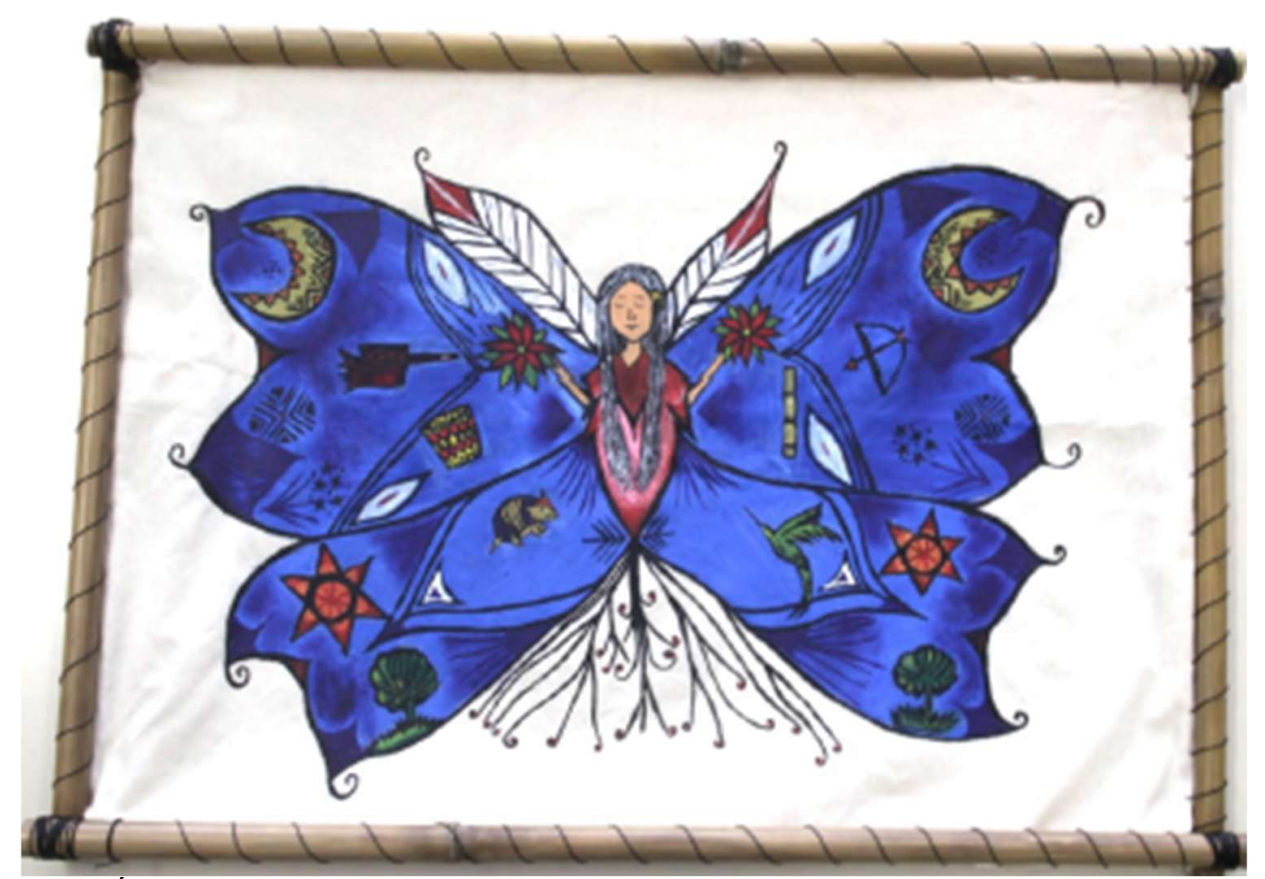

Fonte: TIMÓTEO, Gennis. Djatchy re noi veima (menopausa). 2020. Pintura em tela (tinta de estampa e moldura de bambu), página 43.

A anciã transforma-se em uma mulher-borboleta. O processo de metamorfose ocorreu ao longo da sua trajetória, vivenciou experiência importantes, tanto dentro do próprio corpo quanto na interação com a comunidade; aprendeu os sentidos cosmológicos da existência guarani; percebeu a sacralidade de sua relação com a terra. Todos esses acontecimentos contribuíram para o seu amadurecimento até se tornar uma borboleta com asas celestiais, representadas pela cor azul. As asas podem simbolizar o infinito de conhecimentos que foram armazenados no próprio corpo; a espiritualidade de ter a certeza que chegará em um lugar no qual a vida nunca terá fim, após abandonar a veste da anatomia humana; e a eternidade dos seres que estão desenhados.

$\mathrm{Na}$ asa esquerda, vários elementos vivos: lua, petynguá, grafismos, estrela, cesto, tatu e árvore. Alguns desses seres já apareceram em outras telas da autora, influenciando no ciclo do útero (lua, árvore) ou representando o próprio corpo feminino (cesto, grafismo). O petynguá, como explica Belarmino da Silva (2015), é um cachimbo que simboliza a vida Guarani. Existe uma dimensão espiritual e sagrada no artefato, sendo "muito usado ao redor do fogo, quando há conversas com os mais velhos, nos rituais e para expressar o pensamento para a família e para a comunidade" 
(SILVA, 2015, p. 7). Ao lado de outros artefatos, é fundamental para salvaguardar as práticas culturais da comunidade:

\begin{abstract}
O "tempo" guarani foi um dos fatores principais que me faz compreender e sentir a realidade da vida e do ser guarani através desse símbolo essencial - o petynguá. Dessa forma posso afirmar de que a cultura guarani está preservada em variados símbolos materiais (como, por exemplo: opy - casa de reza, artefatos, artesanato, instrumentos musicais etc.), sendo que o central é o petynguá (SILVA, 2015, p. 16).
\end{abstract}

O material apresenta um valor simbólico, por isso os artefatos também são vivos. No caso da mulher na menopausa, ela chegou a uma idade da sua existência em que absorveu diversos conhecimentos espirituais. Por isso, aprende e transmite a potência do uso do petynguá e da fumaça emitida pelo artefato.

$\mathrm{Na}$ asa direita, além da reprodução de elementos observados no lado esquerdo, arco e flecha, takuapu e beija-flor são observados. É importante lembrar que o beija-flor apareceu na primeira tela como animal responsável por depositar as sementes da fertilidade no útero feminino. O objeto que se assemelha a uma flauta (takuapu) é o elemento menos conhecido que compõe a asa. Em forma de bastão de bambu, trata-se de um instrumento musical utilizado pelas mulheres em cerimônias que acompanham os cantos ritmicamente ao baterem o takuapu no chão.

Todos os seres que compõem o azul celestial das asas estão presentes na cosmologia guarani, desempenhando um papel importante para a cultura do povo. Cabe destacar também as flores que estão nas mãos das anciãs e sugerem o poder de cura das plantas, uma sabedoria dominada pelas anciãs da comunidade. A mulher-borboleta conhece os segredos da mata e os encantos das folhas, com isso consegue ajudar as pessoas que sofram com alguma enfermidade.

$O$ rosto sereno da velha precisa ser analisado. Com os olhos fechados e um leve sorriso na boca, a mulher atingiu um alto nível de plenitude na sua existência. A metamorfose experimentada, tal como acontece com a borboleta, Ihe fez sair do casulo e abrir as asas que estavam em formação. Depois de tanto tempo aprendendo, escutando, vivenciando mudanças no corpo, a anciã sai do casulo tranquila, com uma expressão facial serena, pois acumulou sabedoria sobre si, a respeito da cultura do seu povo e acerca da força feminina.

\title{
Mulher-terra-cesto-borboleta: transfigurações do corpo feminino
}

As artes produzidas por indígenas têm conseguido traduzir um fragmento da complexidade que envolve os conhecimentos desses povos, nos quais a relação é um elemento essencial na interação com o universo. 
Ou seja, diferentemente de como ocorre na perspectiva hegemônica, não é possível compartimentalizar o saber, pois um fazer está conectado com diferentes práticas.

Os artefatos e grafismos são exemplos de como a atividade artística indígena por vezes desenvolve uma função para além da representação simbólica. Técnicas são empregadas na elaboração de cestos, colares, cerâmicas, objetos que combinam a forma de serem construídos com a função de servirem para uso na comunidade. Os grafismos apresentam uma dimensão visual que é inscrita no corpo das pessoas, lembrando algumas informações sociais e evocando circunstâncias específicas para o uso de cada desenho. Os traçados devem ser compreendidos dentro da história e cultura de cada povo, que cria os seus significados e partilham no grupo.

Contemporaneamente, cada vez mais se torna comum a possibilidade de os indígenas se utilizarem de linguagens comuns no contexto não indígena. Ampliar os instrumentos de expressão contribui para que a circulação das produções alcance outros públicos e possibilite à sociedade nacional ter contato com as perspectivas indígenas. Gennis Timóteo (2020) integra o movimento de demarcar espaço nos territórios acadêmicos e das artes visuais, buscando estabelecer pontes de diálogo entre o saber ancestral e o conhecimento dominante. Escrever uma investigação refletindo sobre o modo como o povo Guarani pensa as transformações do corpo de mulher é um gesto de rasura dentro da universidade, buscando construir um encontro respeitoso entre as culturas.

Em suas telas, Timóteo (2020) convida o público a perceber que o ciclo de vida feminino envolve diversos seres e a mulher é múltipla: mulher-terra, se pensarmos no momento da primeira menstruação, quando a terra do útero começa a se tornar fértil; cesto, já que foi criada a partir desse artefato e ele é capaz de gerar outras vidas; mulher-borboleta, no auge das transformações, quando a anciã já aprendeu os conhecimentos celestiais, dos animais, artefatos e das plantas. As transformações do corpo são também espirituais e demandam cuidado, seguindo as orientações da sabedoria milenar Guarani.

Pintar é ativar diversas esferas: produção de conhecimento (realizado na monografia); narrativas ancestrais; história das mulheres da própria família; cosmologia Guarani. Cada tela expressa a relação entre esses campos, entrelaçando pesquisa, arte, cultura, saúde e ciência. Assim, as poéticas visuais de Gennis Timóteo (2020) convidam o público a deslocar o pensamento, expandir percepções, compreender a filosofia da vida em relação e mergulhar nas transfigurações do corpo feminino. 


\section{Referências bibliográficas}

APURINÃ, Kuawá. Entrevista. Revista Diversidade e Educação, v.7, n. especial, p.11-20, Out. 2019. Disponível em: < https://periodicos.furg.br/divedu/article/view/9525/6175 > Acesso em: 14 mai. 2021.

GLISSANT, Édouard. Introdução a uma poética da diversidade. Tradução de Enilce do Carmo Albergaria Rocha. Juiz de Fora: Editora UFJF, 2005.

GLISSANT, Édouard. Poética de la Relación. Traducción: Senda Inés Sfereo y Ana Paula Penchaszadeh. Bernal: Universidad Nacional de Quilmes, 1 ed., 2017.

KAMBEBA, Márcia Wayna. Comunicação milenar: os grafismos. In:_. Saberes da floresta. São Paulo: Jandaíra, 2020, p. 46-54.

KRENAK, Ailton. Ideias para adiar o fim do mundo. São Paulo: Companhia das Letras, 2019.

KRENAK, Ailton. A vida não é útil. Pesquisa e organização: Rita Carelli. São Paulo: Companhia das Letras, 2020.

LAGROU, Els; VELTHEM, Lucia. As artes indígenas: olhares cruzados. BIB, São Paulo, n. 87, 3/2018 (publicada em dezembro de 2018), p. 133-156. Disponível em: < https://www.anpocs.com/index.php/bib-pt/bib-87/11596-as-artes-indigenas-olharescruzados/file >. Acesso em: 20 mai. 2021.

MENDEZ, Léo; TUPINAMBÁ, Célia (Direção). Cipó Tupi. Cine Kurumin 2021. 18 min., DOC, 2021, Brasil.

FAGTAR - A FORÇA DELAS. Expressões (Gennis Timóteo). Fagtar - a força delas. Disponível em: < https://fagtar.org/expressoes/expogennis/ >. Acesso em: 10 mai. 2021.

RANGEL, Lucia Helena. Desafios da figuração do invisível (apresentação). In:_ MENENDEZ, Larissa Lacerda. Iconografias do invisível: a arte de Feliciano e Luís Lana. São Paulo: Annablume; Fapesp; 2009, p. 11-13.

SILVA, Belarmino da. Petyngua - símbolo da vida Guarani. Trabalho de conclusão de curso (graduação). Universidade Federal de Santa Catarina, Licenciatura Intercultural do Sul da Mata Atlântica, Florianópolis, 2015. Disponível em: < https://licenciaturaindigena.paginas.ufsc.br/files/2015/04/Belarmino-da-Silva.pdf $>$. Acesso em: 12 mai. 2021.

TIMÓTEO, Gennis Ara'i Martins. Kunhangue arando reko ta'ánga re a'egui nhembopara: sabedoria dos ciclos de vida das mulheres guarani em pinturas e palavras. Trabalho de conclusão de curso (graduação). Universidade Federal de Santa Catarina, Licenciatura Intercultural do Sul da Mata Atlântica, Florianópolis, 2020. Disponível em: < 
Espaço Ameríndio

https://repositorio.ufsc.br/bitstream/handle/123456789/204678/TCC\%20Gennis\%20Martin s\%20Timoteo $\% 20$ Ara $\% 27 i \% c c \% 81 \% 20$.pdf? sequence $=1 \&$ isAllowed=y $>$. Acesso em: 10 mai. 2021.

VELTHEM, Lucia. Artes indígenas: notas sobre a lógica dos corpos e dos artefatos. Textos escolhidos de cultura e arte populares, Rio de Janeiro, v.7, n.1, p. 19-29, mai. 2010. Disponível em: < < https://www.epublicacoes.uerj.br/index.php/tecap/article/view/12052/9434 >. Acesso em: 29 mai. 2021.

Recebido em: 30/05/2021 * Aprovado em: 10/11/2021 * Publicado em: 23/12/2021 